\title{
Does Graph Design Matter To CPAs And Financial Statement Readers?
}

\author{
Deanna Oxender Burgess, Florida Gulf Coast University \\ William N. Dilla, Iowa State University \\ Paul John Steinbart, Arizona State University \\ Todd M. Shank, University of South Florida, St. Petersburg
}

\begin{abstract}
We asked CPAs and financial statement readers if they believe distorted graphs influence judgments and if they think there is a need for standards governing their presentation and attestation in annual reports. We consider these important questions because decades of studies document that distorted graphs commonly appear in annual reports even though there is considerable evidence that such graphs influence readers' judgments. Our results show that professionals are aware of the potential influence of graphical distortion, believe that standards are needed to assist in preparing graphs of financial information to be included in annual reports, and agree that auditors should be required to provide assurance about the accuracy of such graphs.
\end{abstract}

\section{INTRODUCTION}

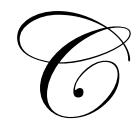

orporate annual reports often contain graphs of financial data. These displays are typically used to help readers quickly see trends and relationships in the data. Design theorists argue that graphs can facilitate decision making when they are properly designed, but that improperly designed graphs can potentially mislead the reader (Bertin 1983; Henry 1995; Kosslyn 1989, 1994; Tufte 1983, 1990, 1997). A disturbing number of studies over a 20-year span report that annual reports in the United States contain graphs that do not follow good graph design principles (Burgess 2003; Johnson et al. 1980; Steinbart 1989). Moreover, the problem is not confined to the United States; numerous studies document the existence of improperly designed graphs in annual reports in many other countries (Beattie and Jones 1992, 1997, 1999, 2000a, 2001; Courtis 1997; Frownfelter and Fulkerson 1998; Frownfelter-Lohrke and Fulkerson 2001; Mather et al. 1996) and also in IPO prospectuses (Mather et al. 2000).

Although the existence of improperly designed graphs in annual reports is well-documented, standardsetting bodies have paid relatively little attention to this issue. In response to empirical evidence of the problem, the United Kingdom's Accounting Standards Board issued a Discussion Memorandum (ASB 2000) suggesting specific standards for the design of graphs of financial data in annual reports. Yet no definitive standards have been issued. In the United States, Statement on Auditing Standards Number 8 (AICPA, 2004) holds auditors responsible for determining whether "other information" included in annual reports, such as graphs, is materially inconsistent with the financial statements. No explicit guidance is provided, however, to assist the auditor in determining whether such "other information" is or is not materially inconsistent with the financial statements, nor is any guidance given with respect to graphical design principles.

The lack of attention given to standards governing the design of graphs in annual reports is puzzling. Steinbart (1989) reported more than ten years ago that companies with a decline in net income are more likely to distort graphs in their annual reports than companies that have an increase in net income. More recently, participants in an experiment by Tractinsky and Meyer (1999) purposefully designed graphs differently when asked to persuade readers with the information versus help readers make good decisions. There is also evidence that altered graphs can 
change readers' perceptions (Beattie and Jones 2002a, 2002b; Burgess 2003) and even lead to different choices in a simple investment task (Arunachalam et al. 2002).

Standard setters and regulatory agencies are unlikely to take action until they perceive the existence of a problem. For example, recent changes in corporate governance structures mandated by Congress, the SEC, and the major stock exchanges occurred largely in response to the spate of financial accounting and auditing failures associated with Fortune 500 companies during the years 2000 through 2002. Thus, the lack of interest in developing authoritative standards concerning the design and auditing of graphs of financial data in annual reports may reflect a perception that this is not a serious problem. Certainly, if neither financial statement readers nor accounting professionals believe that improperly designed graphs are a problem, standard setters and regulators are unlikely to take action. Consequently, this study examines financial statement readers' and CPAs' beliefs about the effects of graph design and the need for related standards.

Our results indicate that both financial statement readers and CPAs believe that improperly designed graphs of financial data are likely to influence viewer perceptions. In addition, both readers and CPAs who responded to our survey expressed strong support for the creation of standards governing the design of financial graphs in annual reports. They also strongly agreed that auditors should be required to assess compliance with such standards. Thus, this study's results suggest that standard setters and regulators should address the issue of the graph design in annual reports.

\section{GRAPH DESIGN PRINCIPLES AND VIOLATIONS}

There exists a considerable body of literature concerning the proper design of graphs to support decisionmaking (Bertin 1983; Henry 1995; Kosslyn 1989, 1994; Tufte 1983, 1990, 1997). Recently, Hill and Milner (2003) developed a comprehensive set of guidelines for graphs of financial data. These guidelines can be summarized in the general principle that to be accurate, graphs should depict physical measures on the surface of the graph that are directly proportionate to the numerical values being represented (Tufte, 1983). Based on that principle, Steinbart (1989, 61-63) proposed three specific criteria that properly designed graphs of financial data in annual reports should satisfy:

1. The numerical values in graphs must match the values reported in the financial statements.

2. The portrayed magnitude of a change or trend in a graph should match the actual quantitative change or trend in the data.

3. The graph should not use formatting or special effects to obfuscate any significant changes in the data or specific data values.

Graphs in annual reports almost always include accurate numerical data (Beattie and Jones 1992, Courtis 1997, Johnson et al. 1980; Jones and Beattie 1997; Steinbart 1989), thereby satisfying Steinbart's first criterion for financial graph accuracy, but frequently portray the physical attributes of the graph in a manner that violates criteria two and three. Numerous examples can be found around the world: Frownfelter-Lohrke and Fulkerson (2001) summarize current and previous research findings spanning decades that indicate improperly constructed graphs occur in $26 \%$ to $52 \%$ of annual reports. Four examples of the types of improperly designed graphs that frequently occur in annual reports follow.

\section{Distortion Type 1: Exaggeration Of An Increasing Trend}

Figure 1 shows an example of how changing the beginning point of the vertical scale affects the visual presentation of an increasing trend. The graph on the left is correctly drawn. The vertical scale begins at zero; consequently the change in the heights of the bars representing the data points is proportional to the change in the actual net income over time. In contrast, the graph on the right begins the vertical scale at $\$ 1,000$. Altering the vertical scale origin exaggerates the visual magnitude of the change in the data. The bar depicting net income in year 5 is almost four times as tall as the bar depicting net income in year 1, creating a visual impression that net income has increased by almost 300 percent. The actual change in net income, however, is only 64 percent. 
Distortion of Increasing Trend

Accurately Drawn Graph

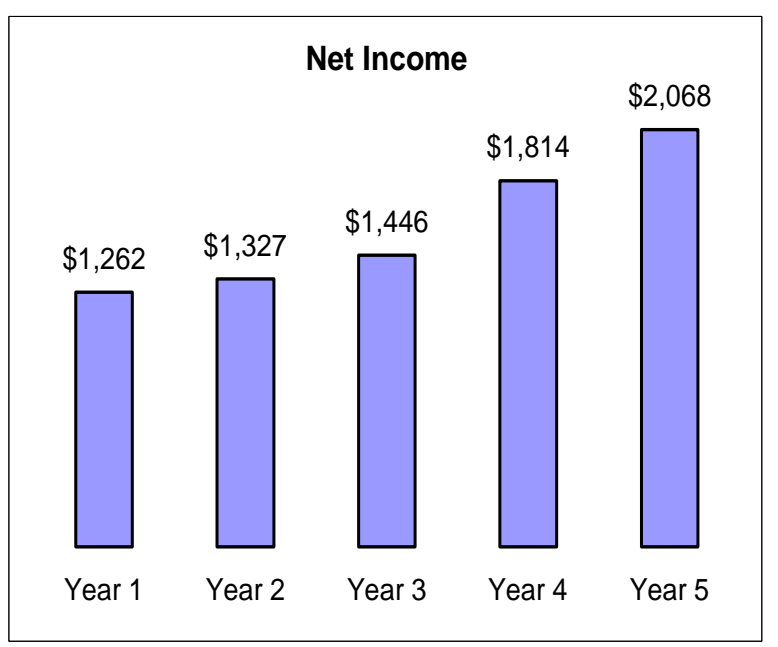

FIGURE 1

Distorted Graph (Vertical Scale Begins at \$1,000)

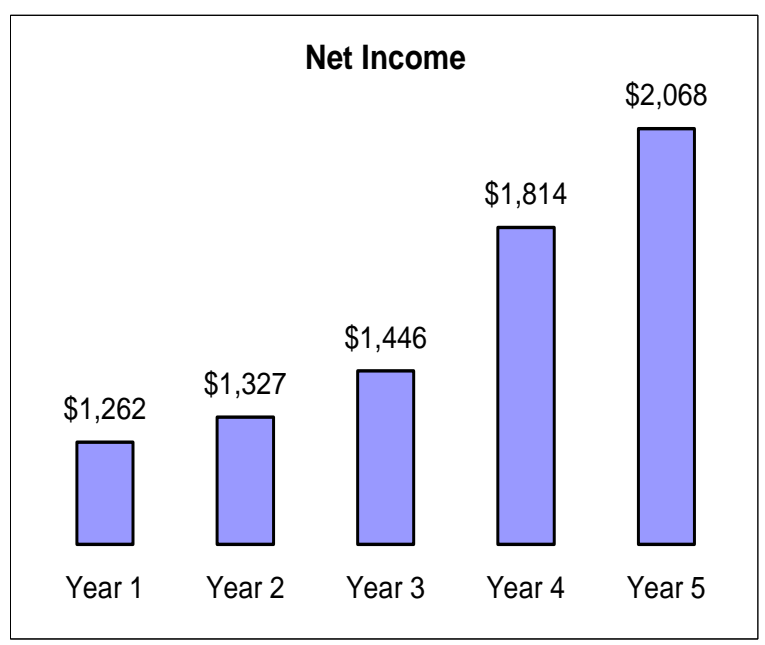

\section{Distortion Type 2: Masking a Declining Trend}

Figure 2 shows how beginning the vertical axis at a point below zero can mask a declining trend. The graph on the left is correctly drawn. The vertical scale begins at zero, which ensures that the change in the relative heights of the bars is proportional to the actual numeric change in net income. In contrast, the graph on the right masks the magnitude of the declining trend because the vertical axis begins at $-\$ 1,000$. As a result, the change in the heights of the bars depicts a decline in net income of approximately $25 \%$, whereas net income actually declined by almost $39 \%$. In this case, the alteration is accomplished by adding fictitious data to the chart (beginning the vertical scale at a negative number even though only positive numbers are included in the graph).

Distortion of Decreasing Trend Accurately Drawn Graph

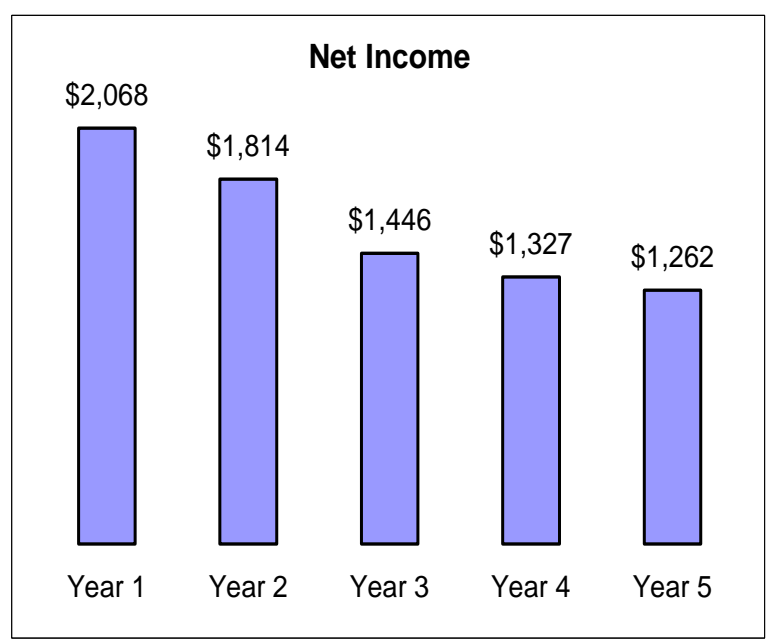

\section{FIGURE 2}

Distorted Graph (Vertical Scale Begins at \$-1,000)

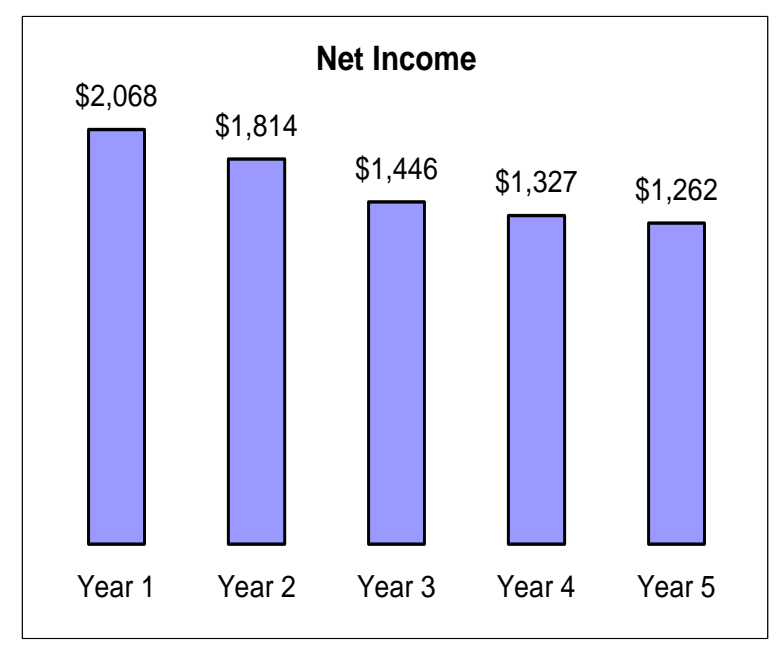




\section{Distortion Type 3: Reverse Chronological Order}

Figure 3 shows another type of graph distortion that is found in some annual reports. Although financial statements do sometimes present tables in which the most recent year's data is on the left, we normally expect that graphs of change over time follow the English language convention of proceeding from left-to-right. The graph on the left obeys that convention, but the graph on the right presents the data in reverse chronological order. Consequently, the graph on the right initially creates the impression of an increasing trend; only after reading the labels on the horizontal axis does the viewer realize that this initial impression is wrong.

Year Reversal Distortion

Normal Left-to-Right Sequence

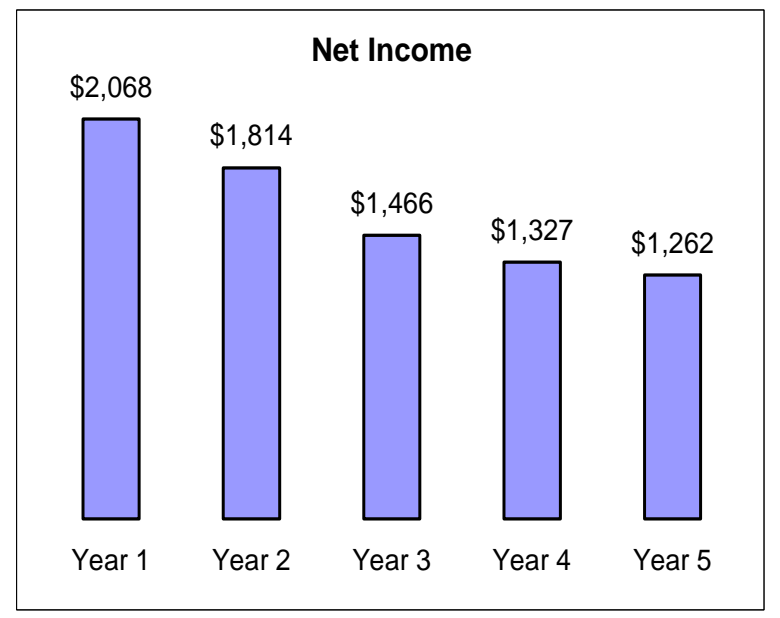

\section{FIGURE 3}

\section{Reverse Right-to-Left Sequence}

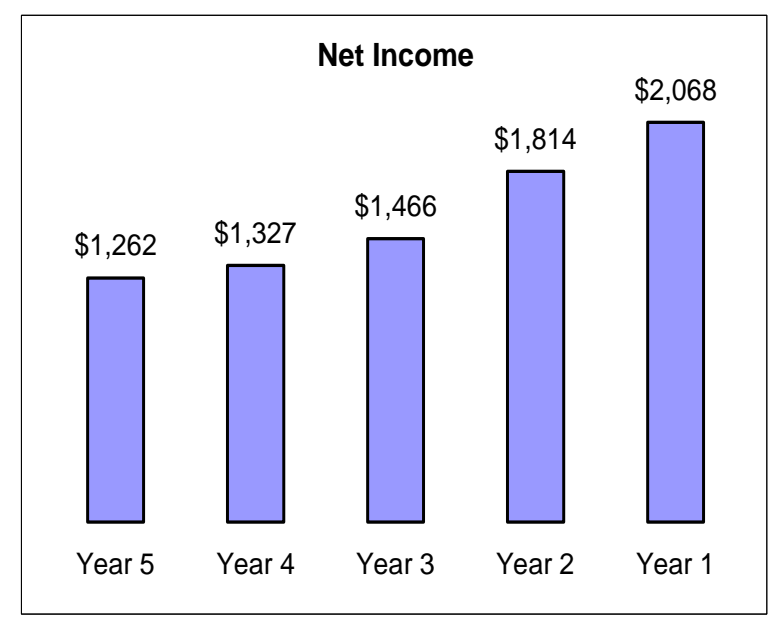

\section{Distortion Type 4: Omission of Negative Values}

Figure 4 shows another type of graph distortion: failure to explicitly graph negative values. The graph on the left depicts the negative net income in year 3 with a bar that extends down from the horizontal axis. The graph on the right does not. Not including the negative bar makes the loss in year 3 less visually salient.

Omission of Negative Values

Negative Values Graphed

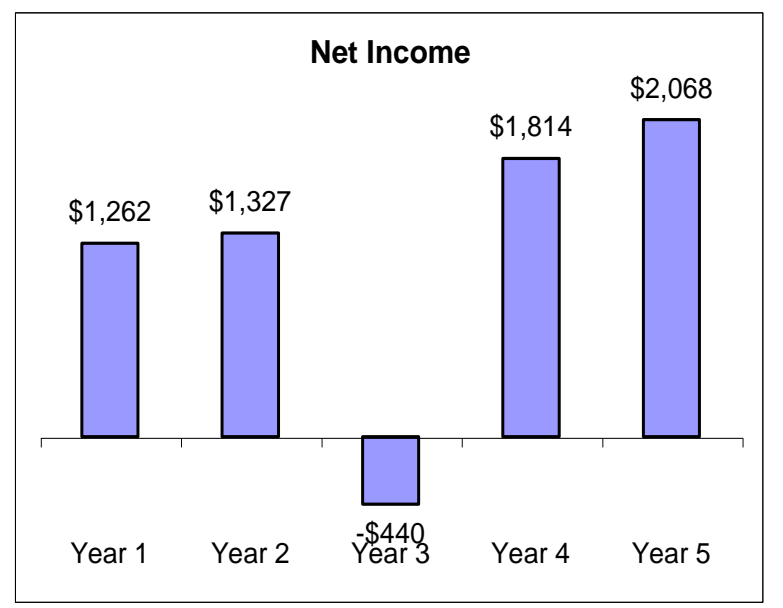

\section{FIGURE 4}

Negative Values Omitted

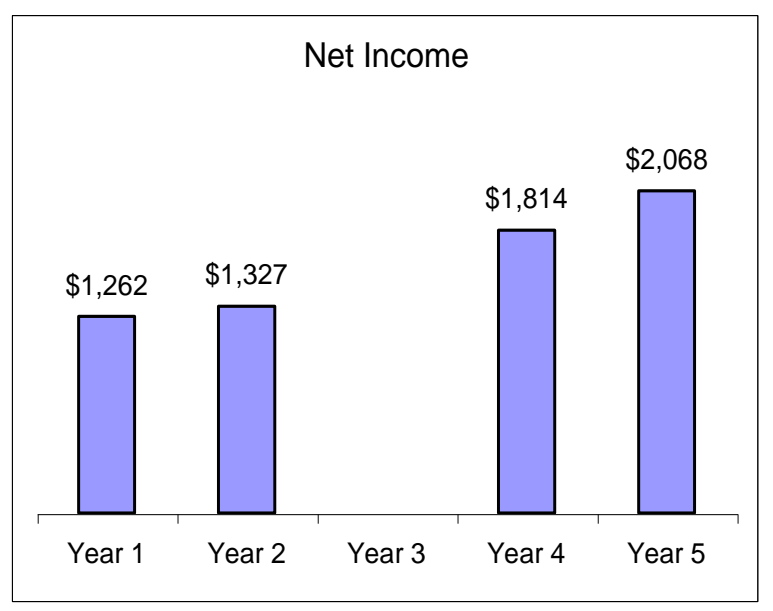




\section{PERCEPTIONS OF FINANCIAL STATEMENT READERS AND CPAS}

The distorted graphs in Figures 1-4 create more favorable visual impressions of the change in the underlying data than is warranted by the numbers alone. But does it matter? An experiment by Tractinsky and Meyer (1999) showed that people designed graphs differently depending upon whether their goal was to persuade or provide assistance in making decisions. This suggests that preparers believe that graph design matters. Several recent experiments provide evidence that such belief is warranted. Beattie and Jones (2002a, 2002b) and Burgess (2003) found that distorted graphs significantly changed viewers' perceptions of the data, and Arunachalam et al. (2002) report that distorted graphs altered viewers' investment choices.

As noted earlier, distorted graphs appear in published annual reports all over the world. There is growing evidence that companies are increasingly using annual reports as public relations tools (Graves et al. 1996; Hanson 1989; Hopwood 1996; Lee 1994; Squiers 1989). This suggests that the existence of distorted graphs in annual reports may represent attempts to influence investors' perceptions of company performance. In turn, that possibility suggests that there may be a need for standards concerning the proper design of graphs of financial data that are included in annual reports, as well as a requirement that auditors evaluate whether any graphs included in annual reports are visually consistent with the audited financial statements. To date, however, standard setters have not issued any guidelines for graphical financial reporting or for the audit of such graphs. This lack of authoritative guidance may be the result of a lack of awareness and interest in this issue. Therefore, we designed a survey to measure both CPAs' and financial statement readers' opinions about the effects of distorted graphs, the ethicality of including such graphs in annual reports, and the need for standards concerning the graphical presentation of financial data in annual reports. The survey was designed to answer the following research questions:

\section{PERCEPTION}

RQ 1a: Do CPAs and readers believe distorted graphs are likely to influence viewers' perceptions of financial statement data?

RQ 1b: Do those opinions differ for different types of graph distortions?

\section{ETHICS}

RQ 2a: Do CPAs and readers believe it is unethical to include distorted graphs in annual reports? RQ 2b: Do those opinions differ for different types of graph distortions?

\section{STANDARDS}

RQ 3a: Do CPAs and readers believe standards are needed for graphical reporting?

RQ 3b: Do CPAs and readers believe that auditors should be required to provide assurance on graphs included in financial statements?

\section{THE SURVEY}

The survey was six pages in length. The cover page explained that at least 10 percent of annual reports contain graphs of financial data that do not conform to principles of graph design and that we were interested in the respondent's opinion about such graphs. The next four pages presented pairs of distorted and nondistorted graphs, each pair illustrating the effects of one of four types of graph design violations (see Figures $1-4$ ). One half of the instruments presented the distorted graph on the left side of the page; the other half presented the distorted graph on the right. Each page had a heading that stated the relevant graph design principle. Below that heading two graphs appeared, labeled exactly as shown in Figures 1-4. Respondents were then asked to indicate their level of agreement or disagreement with the following five statements:

(1) The two graphs create significantly different perceptions of the data. 
(2) The graph on the left ${ }^{1}$ creates an impression different from what would be created by a quantitative analysis of just the numerical data.

(3) The graph on the left portrays the data in a manner that is significantly inconsistent with the actual numeric change in the data.

(4) Including the graph on the left in an annual report with the financial statements would influence evaluations about the company's performance.

(5) Including the graph on the left in an annual report with the financial statements is unethical.

Figure 5 presents an example of one page of the survey.

\section{Sample Page from Survey}

\section{FIGURE 5}

EXAMPLE: Proposed guidelines for graph design suggest that the vertical axis should always begin at zero in order to provide the most accurate depiction of the trend in the underlying numbers.

THE LEFT chart uses a vertical scale that begins at $\$ 1,000$.

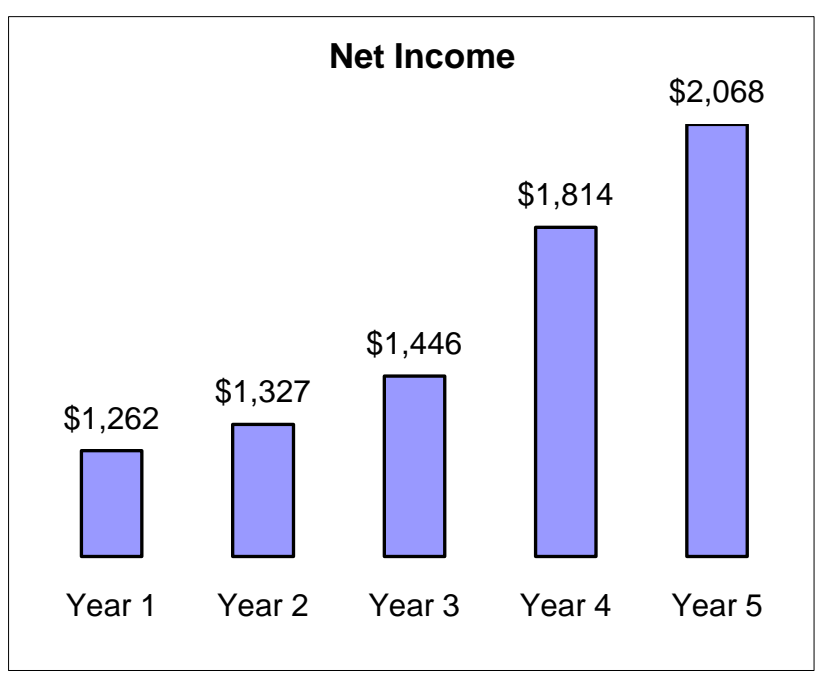

THE RIGHT chart uses a vertical scale that begins at zero.

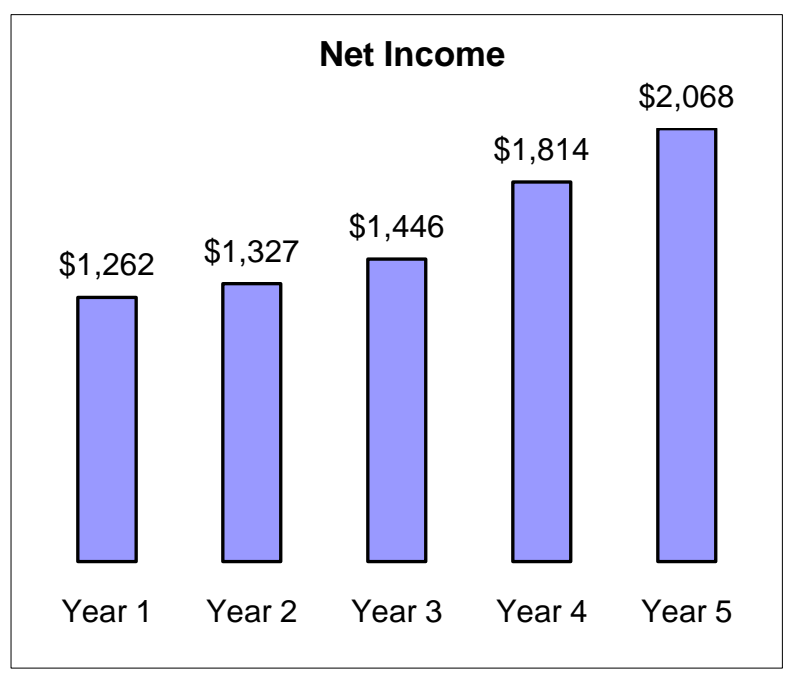

Please rate your agreement with the statements below $(1=$ agree $)$.

\begin{tabular}{|c|c|c|c|c|c|c|}
\hline Agre & & & & & & $a g$ \\
\hline The two graphs create significantly different perceptions of the data. - & 2 & 3 & 4 & 5 & 6 & 7 \\
\hline $\begin{array}{l}\text { The graph on the left creates an impression different from what would be } \\
\text { created by a quantitative analysis of just the numerical data. }\end{array}$ & 2 & 3 & 4 & 5 & 6 & 7 \\
\hline $\begin{array}{l}\text { The graph on the left portrays the data in a manner that is } \\
\text { significantly inconsistent with the actual numeric change in the data }--1\end{array}$ & & & & & & \\
\hline $\begin{array}{l}\text { significantly inconsistent with the actual numeric change in the data.------------ } 1 \\
\text { Including the graph on the left in an annual report with the financial statements }\end{array}$ & 2 & 3 & 4 & 5 & 6 & 7 \\
\hline ould influence evaluations about the company's performance. - - & 2 & 3 & 4 & 5 & 6 & 7 \\
\hline $\begin{array}{l}\text { cluding the graph on the left in an annual report with the financial statements } \\
\text { unethical. }\end{array}$ & 2 & 3 & 4 & 5 & 6 & \\
\hline
\end{tabular}

\footnotetext{
${ }^{1}$ Questions 2-5 always referred to the distorted graph. Thus, instruments with the distorted graph on the left side of the page used the wording as shown; instruments with the distorted graph on the right side used the word right instead of left.
} 
We deliberately stated the proposed guideline and clearly labeled which graph followed that guideline and which did not because we were not interested in whether respondents themselves would be influenced by the graphs, but wanted their opinion about whether each specific type of problem graph would likely influence viewers. The four design violations appeared in random order in the survey to avoid order effects.

The final page of the instrument collected demographic information and asked respondents to indicate their level of agreement with the following questions labeled here as six and seven:

(6) The Financial Accounting Standards Board or SEC should develop standards for the design of financial graphs displayed in the following annual report sections:

Audited financial statements and footnotes

Other sections

(7) The AICPA or SEC should require auditors to evaluate financial graphs for consistency with the financial statements when the graphs are displayed in the following annual report sections:

Audited financial statements and footnotes

Other sections

\section{RESULTS}

\section{Respondent Demographics}

The survey was administered to four groups: 91 CPAs attending a continuing education course sponsored by their state society, 41 executive MBA students at a western university, 18 standard MBA program students enrolled in a second-year investments class at a Midwestern university, and 26 standard MBA students enrolled in the introductory first-year managerial accounting class at a southwestern university. Sixteen of the respondents did not answer all the questions in the survey and were not included in our analyses. Table 1 provides demographic data about the remaining 160 respondents.

Respondent Demographics

Counts (Percentages) Within Each Group

\section{Gender}

Male

Female

Experience Using or Creating Graphs

Never or seldom

Occasionally

Frequently

Years of Work Experience (means)

\section{TABLE 1}

\begin{tabular}{lll}
$\begin{array}{l}\text { CPAs } \\
(\mathrm{n}=79)\end{array}$ & $\begin{array}{l}\text { Executive MBAs }(\mathrm{n}= \\
39)\end{array}$ & $\begin{array}{l}\text { Regular MBAs } \\
(\mathrm{n}=42)\end{array}$ \\
\hline & & \\
46 & 32 & 29 \\
$(58.2 \%)$ & $(82.1 \%)$ & $(69.0 \%)$ \\
33 & 7 & 13 \\
$(41.8 \%)$ & $(17.9 \%)$ & $(31.0 \%)$
\end{tabular}

$\begin{array}{lll}37 & 2 & 15 \\ (46.8 \%) & (5.1 \%) & (35.7 \%) \\ 25 & 16 & 16 \\ (31.6 \%) & (41.0 \%) & (38.1 \%) \\ 17 & 21 & 11 \\ (21.5 \%) & (53.8 \%) & (26.2 \%) \\ 21.2 & 14.8 & 6.0\end{array}$


No significant differences were noted between the two standard MBA groups either in demographic data or responses to survey questions, consequently, these groups' responses were pooled. The proportion of males and females varied significantly $(\mathrm{p}=.03)$ by respondent group. All three groups' years of work experience were significantly different from each other $(\mathrm{p}<.01)$, but years of work experience did not differ by gender $(\mathrm{p}=.39)$. Respondent groups also reported different levels of frequency with working with graphs, with executive MBAs reporting a higher level of experience in creating and using graphs than either CPAs or regular MBA students $(\mathrm{p}<$ $.01)$.

\section{Dependent Variables And Preliminary Analyses}

As shown in Figure 5, our survey response scales were labeled with 1 for agree and 7 for disagree. To facilitate interpretation of the results, we transformed the data so that 7 indicates strong agreement and 1 indicates strong disagreement. All reported statistics are based on the transformed data.

The first four questions in the survey asked respondents whether they thought distorted graphs would affect viewers' perceptions of a company's financial data and its performance. Responses to the four questions were correlated (all $r \mathrm{~s}>.47, \mathrm{p}<.01$ ), suggesting that they were measuring one underlying construct. Therefore, we averaged responses to the four questions to create a composite variable that we label PERCEPTION. Cronbach's alpha for this variable was .84 , indicating that it is reliable.

Placement of the distorted graph on the left or right side of the page did not affect responses, so the following data analyses pool the data for both versions of the instrument. Self-reported experience working with graphs did not affect mean responses to any of the questions. Years of work experience was significantly correlated $(\mathrm{r}=.23, \mathrm{p}=.003)$ with opinions about the likely effect of distorted graphs on viewer perceptions: respondents with more work experience agreed more strongly with statements that distorted graphs were likely to influence viewer perceptions. Work experience was not, however, correlated with any of the other response measures $(p>.10)$.

\section{Effects Of Distorted Graphs On Viewer Perceptions (RQ1a And 1b)}

To address whether participants believe distorted graphs are likely to influence viewers (RQ1a)), we compared the mean value of PERCEPTION for each graph distortion type to the response scale midpoint (4.0). Figure 6 shows that the mean value of PERCEPTION was higher than the scale midpoint $(p<.001)$ for all four distortion types, indicating that our participants on average believe that distorted graphs are likely to influence viewers. To address whether beliefs about the influence of distorted graphs differ by distortion type (RQ1b), we conducted a repeated measures analysis with PERCEPTION as the dependent variable, distortion type as a withinsubjects variable and participant type and gender as between-subjects variables. Table 2 displays the results of this analysis. The significant result for TYPE $(\mathrm{F}(3,152)=7.34 ; \mathrm{p}=.001)$ indicates that perceptions about the influence of distorted graphs differ by distortion type. As shown in Figure 6, the highest value of PERCEPTION was observed for graphs that exaggerate increases in net income (5.14), and the lowest values occurred for graphs that mask declines in net income (4.53) and omit negative numbers (4.47).

\section{TABLE 2}

ANOVA Results

\begin{tabular}{|c|c|c|c|c|c|}
\hline \multicolumn{2}{|l|}{ the } & \multicolumn{2}{|c|}{ PERCEPTION } & \multicolumn{2}{|c|}{ UNETHICAL } \\
\hline Source & df & $\mathrm{F}$ & $\mathrm{p}$ & $\mathrm{F}$ & $\mathrm{p}$ \\
\hline \multicolumn{6}{|l|}{ Within Subjects: } \\
\hline TYPE & 3 & 7.34 & .001 & 3.88 & .01 \\
\hline TYPE x GROUP & 6 & .77 & .59 & .43 & .86 \\
\hline TYPE x GENDER & 3 & .67 & .58 & .05 & .99 \\
\hline TYPE x GROUP x GENDER & 6 & .38 & .89 & .66 & .68 \\
\hline Error & 152 & & & & \\
\hline \multicolumn{6}{|l|}{ Between Subjects: } \\
\hline GROUP & 2 & 4.17 & .02 & 1.01 & .37 \\
\hline GENDER & 1 & 5.80 & .02 & .42 & .52 \\
\hline GROUP x GENDER & 2 & 2.59 & .08 & .46 & .63 \\
\hline Error & 154 & & & & \\
\hline
\end{tabular}


FIGURE 6

Respondents' Opinions That Distorted Graphs Will Influence Perceptions

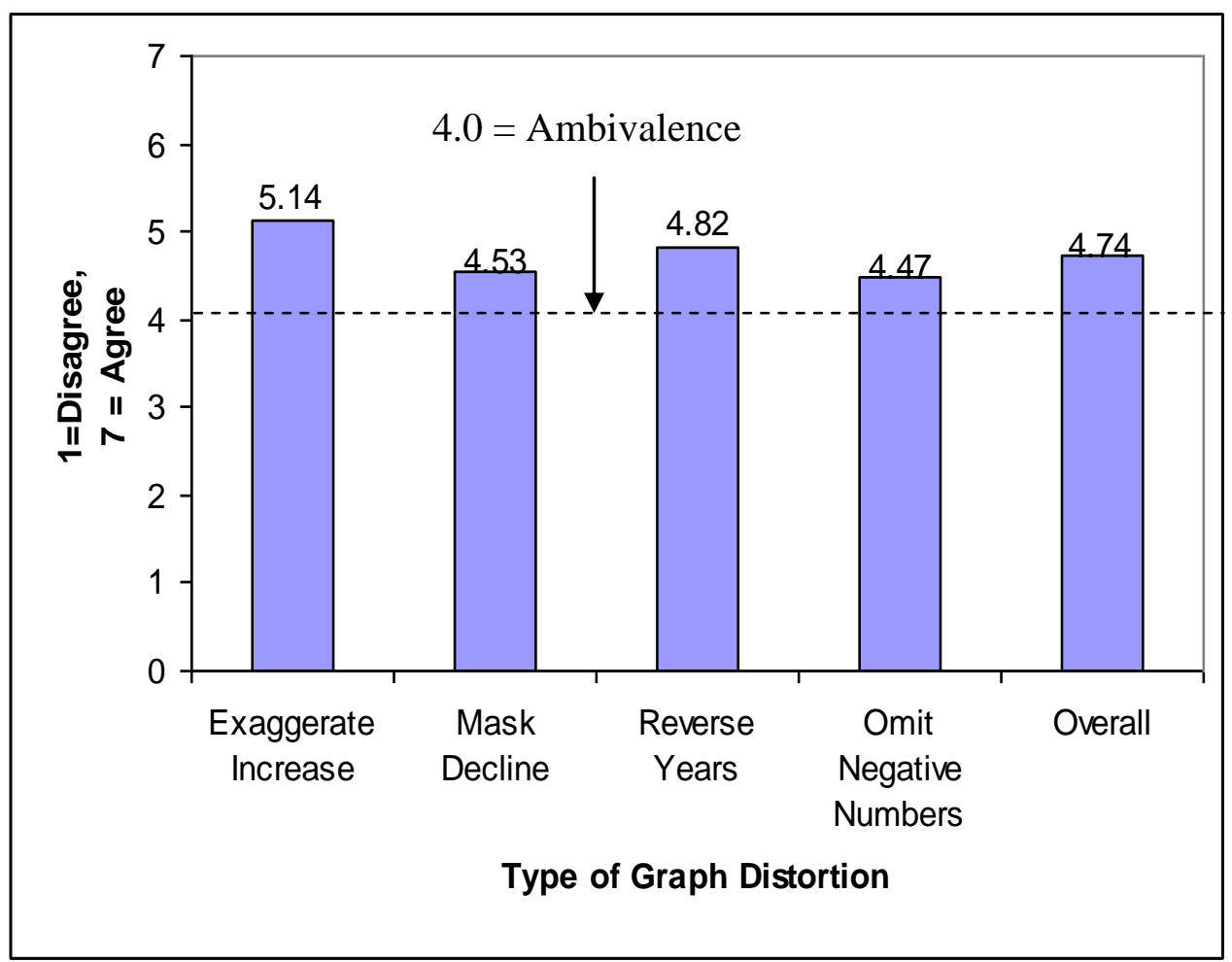

All means are significantly $(\mathrm{p}<.001)$ greater than ambivalent midpoint of 4 .

Table 2 also indicates that opinions about the effect of graph distortions differed by gender and by respondent type. Post-hoc tests of the interaction between gender and respondent type revealed that the difference in opinions between male and female regular MBA students was significant $(\mathrm{p}=.004)$, but that gender did not affect the perceptions of either executive MBAs or CPAs $(p>.10)$. Figure 7 shows that unlike other participant groups, female executive MBA students were ambivalent about whether distorted graphs were likely to influence viewer perceptions and female regular MBA students did not believe that distorted graphs were likely to influence viewer perceptions. 
FIGURE 7

Opinions that distorted graphs will influence viewers by respondent type and group

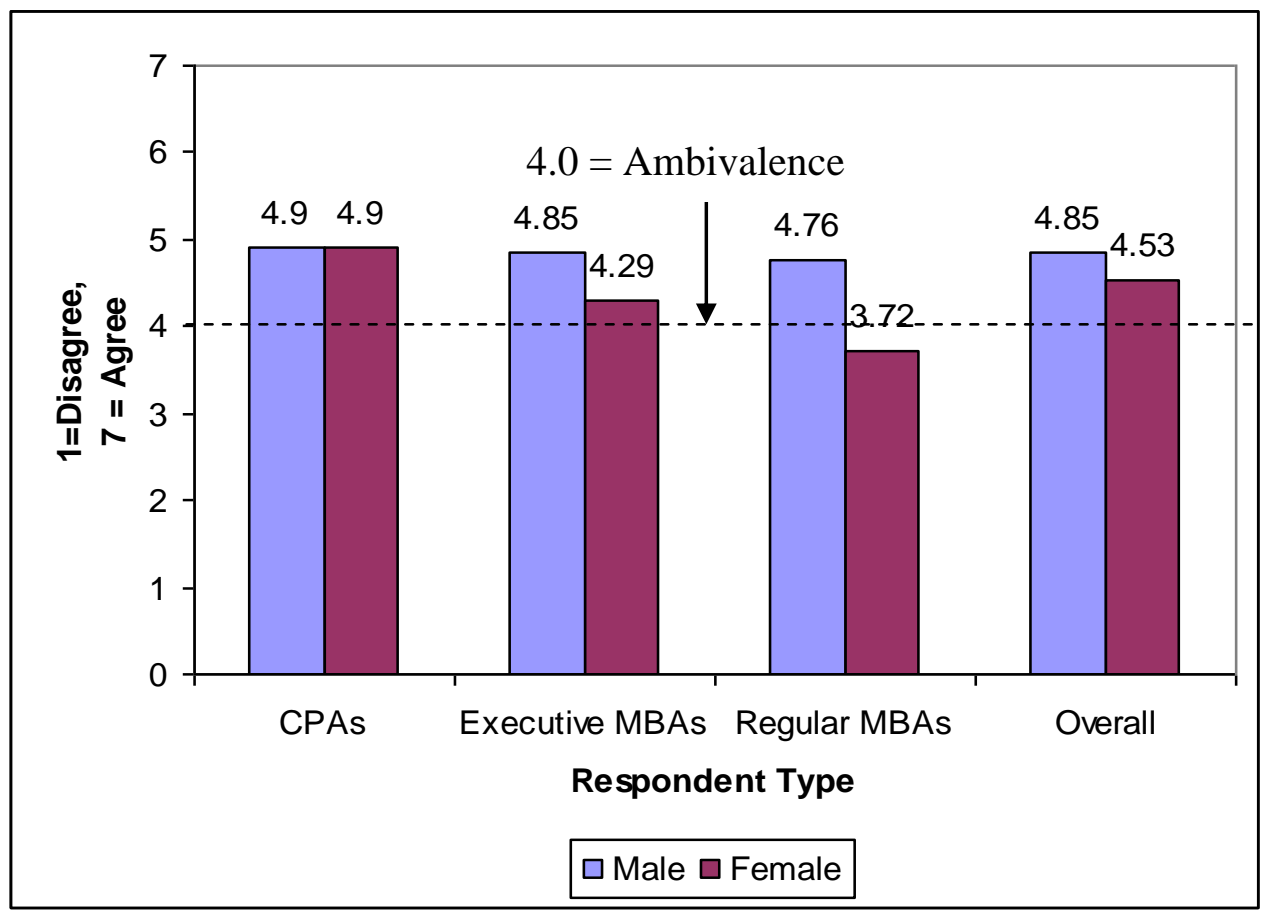

Means for CPAs and male executive MBAs are significantly $(\mathrm{p}<.01)$ greater than the ambivalent midpoint of 4. Mean for female executive MBAs is not significantly different from the ambivalent midpoint of 4 . Mean for female regular MBAs is significantly $(\mathrm{p}=.09)$ less than the ambivalent midpoint of 4.

\section{Ethicality Of Distorted Graphs In Financial Statements (RQ 2a And 2b)}

To address whether participants believe including distorted graphs in financial statements is unethical (RQ2a), we compared the mean value of UNETHICAL for each graph distortion type to the response scale midpoint. Mean values for graphs that mask declines (4.03) and reverse years (4.10) did not differ from the scale midpoint ( $p>.50$ in both cases). Mean responses for graphs that exaggerated increases (3.71) and omitted negative numbers (3.56) were significantly less than the scale midpoint ( $p=.07$ for exaggerated increases; $p=.004$ for omit negative numbers). The results therefore indicate that overall, participants did not believe that including distorted graphs in financial statements was unethical.

To address whether beliefs about the ethicality of distorted graphs differ by distortion type (RQ2b), we conducted a repeated measures analysis with UNETHICAL as the dependent variable, distortion type as a withinsubjects variable and participant type and gender as between-subjects variables. Table 2 displays the results of this analysis. The significant result for TYPE $(F(3,152)=3.88 ; p=.01)$ indicates that perceptions about the ethicality of distorted graphs differ by distortion type. Opinions about the ethicality of including distorted graphs in annual reports did not differ by gender or respondent group.

\section{Graphical Reporting And Assurance Standards (RQ 3a And 3b)}

To address whether participants believe that standards are needed for graphical reporting (RQ 3a) and that auditors should give assurance on financial statement graphs (RQ 3b), we compared the mean response for each relevant question to the midpoint on the response scale. Figure 8 displays the mean responses to these questions. All means were significantly greater than the scale midpoint $(\mathrm{p}<.001)$, indicating agreement both with the need for 
standards for financial statement graphs and for auditors to give assurance on such graphs. Participants indicated higher agreement with requiring standards for graphs appearing in financial statements and footnotes $(\mathrm{m}=5.79)$ than in other sections of the financial statements $(\mathrm{m}=5.39)(\mathrm{p}<.001)$. Similarly, they indicated higher agreement with requiring auditors to perform evaluations of consistency for graphs appearing in financial statements $(\mathrm{m}=5.91)$ than in other sections of the financial statements $(\mathrm{m}=5.44)(\mathrm{p}<.001)$.

FIGURE 8

Respondents' Opinions about the Need for Authoritative Guidance

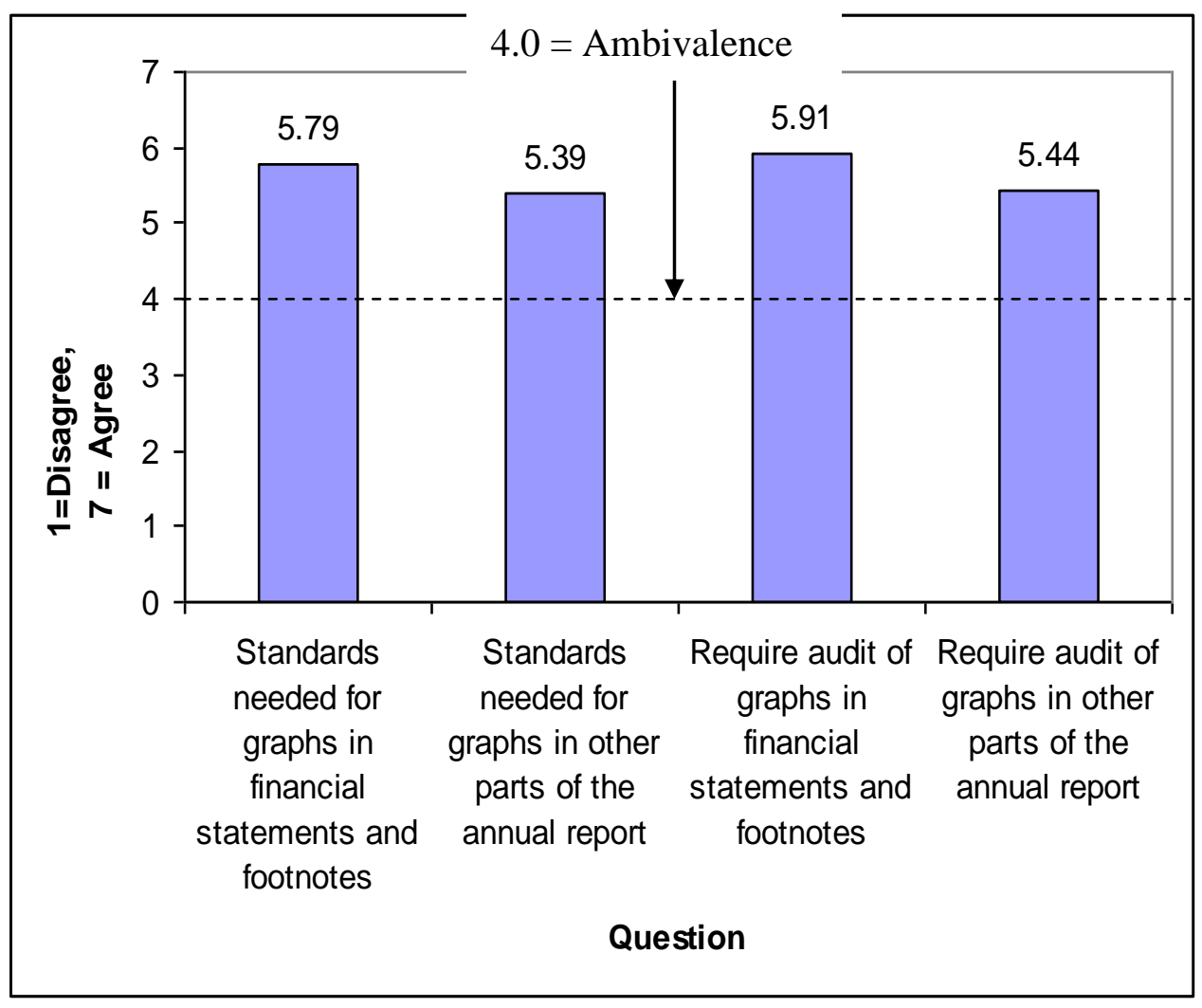

All answers are significantly higher than the ambivalent midpoint of $4(\mathrm{p}<.001)$.

\section{Relationship Between Survey Question Answers}

We also investigated whether participants' opinions about the effects of distorted graphs on viewer perceptions were related to their opinions regarding the ethicality of distorted graphs and the need for presentation and auditing standards regarding such graphs. We did this by correlating each participant's average value for PERCEPTION across all four graph distortion types with their average response for UNETHICAL across all four graph distortion types, and with their responses to the four questions regarding the need for graphical reporting and auditing standards. Participants' average value for PERCEPTION was highly correlated with their average response for UNETHICAL $(\mathrm{r}=.58 ; \mathrm{p}<.001)$ : the more strongly a respondent felt that distorted graphs would influence viewer perceptions, the more strongly they felt that including such graphs in annual reports was unethical. Average values for PERCEPTION and UNETHICAL were correlated with participants' beliefs about the need for graphical reporting standards in financial statements and other sections of annual reports (rs range from .34 to .36; all ps < $.001)$ and with their beliefs about the need for graphs appearing in financial statements and other sections of annual reports to be audited (rs range from .25 to .29 ; all ps $<=.001$ ). 


\section{SUMMARY AND CONCLUSIONS}

We asked CPAs and financial statement readers if they believe distorted graphs would influence viewer perceptions and judgments and if they thought there was a need for standards governing the design of financial graphs included in annual reports. All respondent groups, except females enrolled in executive and regular MBA programs, agreed that distorted graphs were likely to influence viewer perceptions. The total of 20 female MBA respondents represent only $12.5 \%$ of our total respondents. Interestingly, however, neither readers nor CPAs thought that it was unethical to include improperly drawn graphs in annual reports. One possible explanation for this finding is that people do not normally consider exaggerations or omissions of data to be "deceptive" unless they have a priori reasons to believe that the message sender intends to deceive them (Miller and Stiff 1993, 18). Recall that the distorted graphs all included accurate data values. Thus, respondents to our study may have felt that such graphs were not intended to deceive and, therefore, were not unethical but merely represented permissible attempts to "put the best face" on the underlying data. Nevertheless, both readers and CPAs who responded to our survey strongly support the development of standards for graphing financial information, and both CPAs and readers agree that auditors should be required to assess compliance with those standards.

It is noteworthy that in recent years a growing number of researchers have argued that companies appear to be using annual reports as advertising and public relations tools, employing graphs and other techniques to guide and direct readers' attention to specific dimensions of the organization's performance (Graves et al. 1996; Hanson 1989; Hopwood 1996; Lee 1994; Squiers 1989). Indeed, there is evidence of a positive relationship between firm performance and the inclusion of graphs of financial data in annual reports: companies were more likely to include such graphs when income and sales are increasing than when they are decreasing (Beattie and Jones 2002b). There is also evidence that companies are more likely to include distorted graphs of financial data in their annual reports when their net income has declined than when it has increased (Steinbart 1989). Thus, it appears that companies use graphs in annual reports in an attempt to manage impressions. Respondents to our survey agree that such attempts are likely to influence annual report readers' perceptions. Therefore, it is not surprising that respondents to our survey strongly agree that there is a need to develop standards for the graphical presentation of financial information and that auditors should assess whether graphs in annual reports comply with those standards.

A limitation of our findings is that they reflect only the opinions of respondents concerning the likely effects of different types of graphs on the decision-making process of financial statement users. One can justifiably argue that standard setters should not overreact to such perceptions, without adequate empirical evidence that there is indeed a real problem. Several recent studies, however, provide evidence that improperly designed graphs can indeed influence reader perceptions (Beattie and Jones 2002b; Burgess 2003) and even alter decision makers' choices (Arunachalam et al. 2002). In addition, Tractinsky and Meyer (1999) found that graph designers made different choices when their task was to produce graphs for the purpose of helping someone make the best possible decision than when their objective was to influence the decision maker's interpretation of the data. Thus, there is reason to believe that our respondents' opinions concerning the need to develop standards for the graphical presentation of financial data are warranted.

In conclusion, more than 20 years of research has documented the existence in annual reports of graphs of financial data that are designed in a manner that may influence financial statement readers' perceptions. To date, however, standard setters have taken little action in this area. The results of our study suggest that both CPAs and financial statement readers strongly support the development of standards for graphing financial data and the requirement that auditors assess compliance with those standards. Numerous guidelines have been proposed in the graph design literature, including a checklist for proper graph design developed by Hill and Milner (2003). There is support for developing authoritative standards for graphical financial reporting. It is time for standard setters to act accordingly.

\section{REFERENCES}

1. American Institute of Certified Public Accountants (AICPA). 2004. Codification of Statements on Auditing Standards. New York: American Institute of Certified Public Accountants. 
2. Arunachalam, V., Pei, B.K.W., and Steinbart, P.J. 2002. Impression management with graphs: Effects on choices. Journal of Information Systems. 16(2): 183-202.

3. ASB. 2000. Year-end financial reports: improving communication. Discussion paper. (February). London: Accounting Standards Board.

4. Beattie, V., and Jones, M.J. 1992. The use and abuse of graphs in annual reports: a theoretical framework and empirical study. Accounting and Business Research (Autumn): 291-303.

5. 1997. A comparative study of the use of financial graphs in the corporate annual reports of major US and UK companies. Journal of International Financial Management and Accounting 8(1): 33-68.

6. 1999. Do Australian graphs give a true and fair view? Abacus 35(1): 46-76.

7.

8. . 2000a. Impression management: the case of inter-country financial graphs. Journal of International Accounting, Auditing \& Taxation 9(2): 159-183. 2000b. Changing graph use in corporate annual reports: A time-series analysis.

9. Contemporary Accounting Research 17 (Summer): 13-22.

9. 2001. A six-country comparison of the use of graphs in annual reports. International Journal of Accounting 36: 195-222.

10. 2002a. Measurement distortion of graphs in corporate reports: an experimental study. Accounting, Auditing \& Accountability Journal 15(4): 546-564.

11. .2002b. The Impact of Graph Slope on Rate of Change Judgments in Corporate Reports. Abacus 38(2): 177-199.

12. Bertin, J. (1983). The Semiology of Graphics. Madison, WI: University of Wisconsin Press.

13. Burgess, D. (2003). Graphical Sleight of Hand. Journal of Accountancy 193(2): 45-51.

14. Courtis, J.K. 1997. Corporate annual report graphical communication in Hong Kong: effective or misleading? The Journal of Business Communication 34(3): 269-288.

15. Frownfelter, C.A., and Fulkerson, C.L. 1998. Linking the incidence and quality of graphics in annual reports to corporate performance: an international comparison. Advances in Accounting Information Systems 6: 129-151.

16. Frownfelter-Lohrke, C.A. and Fulkerson, C. L. 2001. The incidence and quality of graphics in annual reports: An international comparison. The Journal of Business Communication 38(3): 337-358.

17. Graves, O.F., Flesher, D. L., and Jordan, R.E. 1996. Pictures and the bottom line: The television epistemology of U.S. annual reports. Accounting Organizations and Society 21(1): 57-88.

18. Hanson, J.D. 1989. Developments in financial reporting over the last 20 years. In Skerratt, L.C.L. and Tonkin, D.J. (Eds), Financial Reporting 1988-89: A Survey of UK Published Accounts. London: Institute of Chartered Accountants of England and Wales. pp. 3-13.

19. Henry, G.T. 1995. Graphing Data: Techniques for Display and Analysis, Applied Social Research Methods Series, 36. Sage Publications.

20. Hill, W.Y. and Milner M.M. 2003. Guidelines for graphical displays in financial reporting. Accounting Education 12(2): 135-157.

21. Hopwood, A.G. 1996. Editorial. Accounting, Organizations and Society 21(1): 55-56.

22. Johnson, J.R., Rice, R.R., and Roemmich, R.A. 1980. Pictures that lie: the abuse of graphs in annual reports. Management Accounting (October): 50-56.

23. Jones M. and Beattie V. 1997. Financial Graphs in Corporate Annual Reports: A Review of Practice in Six Countries. London, U.K.: The Institute of Chartered Accountants in England and Wales.

24. Kosslyn, S.M. (1989). Understanding Charts and Graphs. Applied Cognitive Psychology, 3(3): $185-226$.

25. (1994). Elements of Graph Design. New York: Freeman \& Company.

26. Lee, T.A. 1994. The changing form of the corporate annual report. Accounting Horizons (June): $215-232$.

27. Mather, P., Ramsay, A., and Serry, A. 1996. The use and representational faithfulness of graphs in annual reports: Australian evidence. Australian Accounting Review 6(2): 56-63.

28. Mather, P., Ramsay, A., and Stten, A. 2000. The use and representational faithfulness of graphs in IPO prospectuses. Accounting, Auditing and Auditability 13(1): 65-83.

29. Miller, G. R. and Stiff, J.B. 1993. Deceptive Communication. Newbury Park, CA: Sage Publications.

30. Squiers, C. 1989. The corporate year in pictures. In Bolton, R. (Ed.), Contest of Meaning. Cambridge, MA: Massachusetts Institute of Technology, pp. 207-218. 
31. Steinbart, P.J. 1989. The auditor's responsibility for the accuracy of graphs in annual reports: some evidence of the need for additional guidance. Accounting Horizons 3(3): 60-70.

32. Tractinsky, N. and Meyer, J. Chartjunk or goldgraph? Effects of presentation objectives and content desirability on information presentation. MIS Quarterly, 23(3): 397-420.

33. Tufte, E.R. (1983). The Visual Display of Quantitative Information, Cheshire, CT: Graphics Press.

34. _ (1990). Envisioning Information, Cheshire, CT: Graphics Press.

$35 . \quad$ (1997). Visual Explanations, Cheshire, CT: Graphics Press.

\section{NOTES}

